$\$$ Research Square

\title{
The Associations of Urinary DEHP Metabolites Levels, Serum Thyroid Hormones and Thyroid Related Genes Among the Adolescent Students from China - A Cross-Sectional Study
}

\author{
Yaming Zhao \\ Jilin University School of Public Health \\ Xinyue Song \\ Jilin University School of Public Health \\ Shuang Ding \\ Jilin University School of Public Health \\ Wen Qi \\ Jilin University School of Public Health \\ Yuezhu Zhang \\ Jilin University School of Public Health \\ Qi Xu \\ Jilin University School of Public Health \\ Tianyang Zhao \\ Jilin University School of Public Health

\section{Xueting Zhang} \\ Jilin University School of Public Health \\ Xu Li \\ Jilin University School of Public Health
}

\section{Fuju Wu}

Jilin University Second Hospital

Lin Ye ( $\nabla$ jlyelin@163.com )

Department of Occupational and Environmental Health, School of Public Health, Jilin University https://orcid.org/0000-0002-8808-7416

\section{Research Article}

Keywords: Adolescents, DEHP metabolites, Thyroid hormone, Human biomonitoring

Posted Date: June 28th, 2021

DOI: https://doi.org/10.21203/rs.3.rs-580920/v1

License: (c) (1) This work is licensed under a Creative Commons Attribution 4.0 International License. Read Full License

Version of Record: A version of this preprint was published at Environmental Science and Pollution Research on October 28th, 2021. See the published version at https://doi.org/10.1007/s11356-021-16909-5. 


\section{Abstract}

Our study aimed to investigate the associations between DEHP exposure and serum thyroid hormone levels in 347 adolescents and young adults. We measured DEHP metabolites including mono(2-ethylhexyl) phthalate (MEHP), mono(2-ethyl-5-oxohexyl) phthalate (MEOHP), mono(2-ethyl-5-hydroxyhexyl) phthalate (MEHHP), mono(2-ethyl-5-carboxypentyl) phthalate (MECPP) and mono(2-carboxmethyl)hexyl phthalate (MCMHP) in their urine. Total thyroxine (TT4), total triiodothyronine, free triiodothyronine, free thyroxine (FT4), thyroidstimulating hormone and the mRNA levels of thyroid peroxidase $(T P O)$, thyroglobulin $(T G)$, sodium iodide symporter (NIS), thyroid transcription factor 1 (TTF-1) and paired box gene 8 (PAX-8) in serum were measured. The results of statistical analysis showed that urinary DEHP metabolites were generally negatively associated with TT4 levels in serum. In the males, the FT4 levels showed positive associations with urinary MEHP, MECPP, MCMHP, and $\sum D E H P$. The mRNA level of $T G$ was significantly positively correlated with the levels of MECPP, MCMHP and $\sum$ DEHP, while the level of NIS mRNA was significantly positively correlated with the levels of MEOHP. There was a significant positive correlation between TTF-1 mRNA level and urinary MEOHP, MECPP, MCMHP and $\sum$ DEHP.

\section{Introduction}

Di-2-ethylhexyl phthalate (DEHP) is the most common member of phthalates. It is used as plasticizer in many products, especially in blood bags and infusion tubes and other medical devices, and is also common in food and beverage packaging (Earls et al. 2003); architectural and furniture materials, including furniture and vinyl flooring; and perfumed cosmetics and personal care products (Dobrzynska 2016; Koniecki et al. 2011). Because of the overuse of plastic products in life, people can be exposed to DEHP easily. At present, a certain amount of DEHP can be detected in many environmental media (air, sediment, water, soil, etc.)(Gartner et al. 2009). Study has shown DEHP has the endocrine, testicular, ovarian, neural, hepatotoxic, and cardiotoxic effects on animal models and humans in vitro and in vivo(Rowdhwal and Chen 2018). People are mainly exposed to DEHP through food, water, air and intravenous fluids, among which diet is the main way(Schettler 2006). After DEHP enters the intestinal tract, it is metabolized by intestinal esterase into Mono-(2-ethylhexyl) phthalate (MEHP), and then MEHP is preferentially absorbed by the digestive tract, decomposed into mono(2-ethyl-5-oxohexyl) phthalate (MEOHP), mono(2-ethyl-5-oxohexyl) phthalate (MEOHP) and mono(2-ethyl-5 -Hydroxyhexyl) phthalate (Mono(2-ethyl-5-hydroxyhexyl) phthalate,MEHHP), mono(2-ethyl-5-carboxypentyl) phthalate (Mono(2-Ethyl-5-carboxypentyl) phthalate, MECPP) and mono[2(carboxymethyl)hexyl] phthalate (Mono(2-carboxmethyl)hexyl phthalate, MCMHP) and other metabolites. These metabolites can be excreted through urine, feces and sweat, and urine is the main excretion way of DEHP metabolites.

Thyroid is a very important gland in the body and belongs to the members of endocrine organs. The thyroid hormone synthesized and secreted by it play a crucial role in many physiological processes, including fetal and child growth and brain development, as well as energy balance, metabolism, and other functions in the nervous, cardiovascular, pulmonary, and reproductive systems of children and adults (Diamanti-Kandarakis et al. 2009). The synthesis of thyroid hormone uses iodine and tyrosine as the main materials. The synthesis process is mainly to transfer the iodine ions in the blood to the acinar cells and convert them into organic iodine under the action of NIS.Then under the action of TPO and TG, the iodination of tyrosine residues occurs to form monoiodine substitutions and diiodo substitutions, which are then connected to form a large amount of T4 and a small amount of T3, which are stored in the acinar space,then under the action of thyroid stimulating hormone(TSH), it is released from the thyroid into the blood to play an active role(Di Jeso and Arvan 2016; Motonaga et al. 2016). During the anabolism of THs, the integrity of thyroid tissue, iodine absorption and changes in related enzymes will cause abnormal thyroid function (Kloas and Lutz 2006; Shin et al. 2006).

In recent years, the incidence of thyroid-related diseases including goiter, hypothyroidism, hyperthyroidism, thyroid inflammation, and thyroid malignant tumors has continued to increase, threatening human health([Anonymous] 2012). Endogenous factors such as age, gender, genetics, and disease can cause abnormal thyroid function (Aldossari et al. 2019; Spanou et al. 2019). Exogenous factors such as environmental factors and diet (mainly iodine intake) can also interfere with the normal metabolism of thyroid hormones (Han et al. 2019; Vigneri et al. 2017). There are increasing evidences that environmental factors such as endocrine disrupting chemical pollutants can affect thyroid hormone levels and alter thyroid morphology, which possibly lead to autoimmune thyroid diseases and thyroid tumors (Are and Shaha 2006; Huang et al. 2007; Khairy 2004; Nix et al. 2005).Epidemiological studies have found that the exposure of EEDs such as bisphenol A, PCBs and DEHP is significantly related to the level of thyroid hormones in the body, and is closely related to the occurrence of thyroid tumors(Gorini et al. 2018; Zhao et al. 2016). As the most common environmental endocrine disruptor (EED), DEHP can interfere with thyroid hormone homeostasis and reduce thyroid hormone (TH) level, including triiodothyronine (T3), thyroxine (T4), and thyrotropinreleasing hormone (TRH) by activating the Ras/Akt/TRHr pathway, and affect hepatic enzymes which play an important role in thyroid destruction (Ye et al. 2017). Mono(2-ethylhexyl) phthalate (MEHP) is a metabolite of DEHP which also can affect the endocrine disruption of the thyroid by altering a series of genes transcription involved in the HPT axis (Zhai et al. 2014).Study has also shown that DEHP can affect TH level by controlling iodine uptake (Wenzel et al. 2005b). The uptake of iodine by thyroid follicular cells depends on essential 
iodides such as thyroglobulin (TG), thyroid peroxidase (TPO) and crucial proteins such as sodium iodide symporter (NIS), thyroid transcription factor 1 (TTF-1) and paired box 8 (PAX-8) (Altmann et al. 2005; Targovnik et al. 2017). TTF-1 is implicated as an essential autoregulatory component in both positive and negative regulation of the TSHR and appears to be the link between TSH, the TSHR, TSHRmediated signals, TG and TPO biosynthesis, and thyroid hormone formation(Kohn et al. 1995). In the mature thyroid, TTF-1 interacts physically with $P A X-8$ to induce the expression of $T G$ and TPO (Di Palma et al. 2003; Miccadei et al. 2002). The transcription factor $P A X 8$ is a master regulator of thyroid development and function. In the mature thyroid gland, $P A X 8$ induces the expression of thyroid-specific genes such as those encoding TG, TPO, and NIS. The sodium (Na+)/iodide (I-) symporter (NIS) mediates iodide accumulation in the thyroid gland (Esposito et al. 1998; Fabbro et al. 1998; Ohno et al. 1999b). However, whether the expression of TG, TPO, NIS, TTF-1 and PAX-8 can be detected in blood was unclear and it is not clear whether DEHP affects the expression of these genes in the blood.

A cross-sectional association study in the United States revealed that DEHP metabolites, total T4 (TT4), free T4 (FT4), and total triiodothyronine (TT3) were negatively correlated with thyroglobulin $(T G)$, and were positively correlated with thyroid stimulating hormone (TSH) (Meeker and Ferguson 2011). DEHP metabolites and mono-benzyl phthalate (MBzP) were also inversely related to total and free T3 levels, and mono-n-butyl phthalate (MnBP) was inversely associated with total and free T3 in Danish children (Boas et al. 2010). However, most human observations were based on children and adults. Evidences of thyroid disruption among adolescents are very limited especially in Asian population. Adolescence and young adulthood are critical periods of human growth and development, in which any change in endocrine function may cause a long-term effect on the body(Ding et al. 2019). The total intake of phthalates that did not include non-dietary intake was higher in all children than in adults (Katsikantami et al. 2016). As a result, young people are exposed to more phthalates than older people (Lin et al. 2017; Shea and Hlth 2003). Epidemiological studies have shown that phthalates may be related with premature breast development for girls, anti-androgen effects, speeding up and delay of growth and puberty in girls and boys respectively and poor attentional performance (Berger et al. 2018; C Xie et al. 2015). In addition, some epidemiological studies have reported that phthalates may be positively associated with adolescent thyroid dysfunction (Huang et al. 2017a; Robinson and Miller 2015; Trasande et al. 2014). This suggests that exposure to phthalates has a significant effect on the growth and development of children or adolescents and the health effects of DEHP in adolescents cannot be ignored.It is necessary to explore the association between DEHP metabolites and thyroid hormones.

Surveys of the effects of environmental endocrine disruptors exposure in healthy children and adolescents are valuable and may identify factors that contribute to their growth and health. Our study aimed to investigate the association of DEHP metabolites in urine with serum thyroid hormones in adolescent students. For this purpose, data obtained from adolescent students in a university in Jilin Province. In addition, we also detected the mRNA expression of TG, TPO, NIS, TTF-1 and PAX-8 in the blood of these healthy students. The results of this study are useful to confirm the effect of DEHP on thyroid hormones and the association between them among the adolescent students.

\section{Methods}

\section{Participants' recruitment}

This project is a cross-sectional study realized in September 2017 and in collaboration with a university in Jilin province, China that involved newly enrolled students aged 16 to 19 in three faculties used cluster sampling method to investigate. Excluding the patients with diseases of liver, kidney and blood system, those receiving hormone therapy, those with family history of hereditary metabolism, and those with incomplete basic information or biological samples, a total of 347 adolescents were finally included in the study.

This study was approved by the ethics committee of the School of Public Health, Jilin University, China. Each subject was informed of the study protocol and provided written informed consent. If they agreed to be participants of the study, a consent form would be signed by the parent/guardian or the participant aged 18 and over.

\section{Data and sample collection}

Medical history and socio-demographic information were collected using questionnaires with the parent, guardian or participants aged 18 and over. Anthropometric measures (height and weight) and biological samples (blood and urine samples) from the participants were collected on-site at the university hospital. Before collecting samples, participants were required to be in fasting.

Spot urine samples were collected from the participants using $15 \mathrm{~mL}$ polypropylene (non-plasticizer) tubes, which were then transported frozen to the laboratory within $2 \mathrm{~h}$ and stored at $-20^{\circ} \mathrm{C}$ for further analyses. Blood samples for thyroid parameters analyses were collected 
in a $5 \mathrm{~mL}$ EDTA serum separation tube. Blood tubes were then kept at room temperature for a minimum of 30 min and a maximum of an hour, before being centrifuged at $3500 \mathrm{rpm}$ for $10 \mathrm{~min}$ at room temperature.

\section{Urinary DEHP metabolites determination}

Urine samples were analyzed at the laboratory of Jilin Entry-Exit Inspection and Quarantine Bureau. The laboratory was assessed by the Certification and Accreditation Administration of the People's Republic of China (CNCA) with the certificate number 150000128361.

Five DEHP metabolites in the urine of the participants were determined through solid phase extraction (SPE) combined with high performance liquid chromatography tandem mass spectrometry (HPLC-MS/MS). Analytes included secondary oxidized metabolites of DEHP, i.e., mono(2-ethylhexyl) phthalate (MEHP), mono(2-ethyl-5-oxohexyl) phthalate (MEOHP), mono(2-ethyl-5-hydroxyhexyl) phthalate (MEHHP), mono(2-ethyl-5-carboxypentyl) phthalate (MECPP) and mono(2-carboxmethyl)hexyl phthalate (MCMHP). Details of the extraction and analytical procedures are described elsewhere (Ding et al. 2019). Briefly, frozen urine samples were thawed in a $37^{\circ} \mathrm{C}$ water bath and then centrifuged at $4000 \mathrm{rpm}$ for $5 \mathrm{~min}$. After centrifugation, the urine supernatant ( $1 \mathrm{~mL})$ was buffered with $250 \mu \mathrm{L}$ ammonium acetate $(1 \mathrm{~mol} / \mathrm{L})$ and spiked with a $100 \mu \mathrm{L}$ mixture of labeled internal standards of phthalate metabolites (200 ng/mL). Then, $50 \mu \mathrm{L}$ of $\beta$ glucuronidase $(250 \mathrm{U} / \mathrm{mL})$ was added. The urine samples were incubated at $37{ }^{\circ} \mathrm{C}$ overnight in a shaking water bath. After incubation, 40 $\mu \mathrm{L}$ of formic acid and $1 \mathrm{~mL}$ of water were added to the urine sample to end the hydrolysis. The urine was passed by natural gravity through an HLB cartridge that had been activated by $2 \mathrm{~mL}$ of acetonitrile and $2 \mathrm{~mL}$ of $0.5 \%$ formic acid, $3 \mathrm{~mL}$ of $0.5 \%$ formic acid was added to the column to remove impurities. The cartridge was washed sequentially with $3 \mathrm{~mL}$ of acetonitrile, $3 \mathrm{~mL}$ of ethyl acetate and $3 \mathrm{~mL}$ of chloroform. The eluate was collected in a flask and concentrated in a rotary evaporator $\left(40{ }^{\circ} \mathrm{C}\right)$. The concentrated eluate was then dissolved with $1 \mathrm{~mL}$ of $0.1 \%$ formic acid water/acetonitrile (8:2, v/v) and sonicated for $5 \mathrm{~min}$. The liquid was finally filtered through a 0.2 $\mu \mathrm{m}$ filter into the sample bottle for analysis. The detailed information including instruments, reagents, chromatographic conditions and mass spectrometric conditions can be found in Table S1 and Table S2. The sum of DEHP metabolites ( $\Sigma$ DEHP metabolites) was calculated by adding the concentration of these five metabolites and expressed in $\mathrm{nmol} / \mathrm{L}$. Urinary creatinine was determined with a creatinine assay kit (Sarcosine Oxidase Method, China) using a microplate reader.

Concentrations of DEHP metabolites in urine $(\mu \mathrm{g} / \mathrm{L})$ were divided by creatinine concentrations in order to obtain creatinine-corrected concentrations ( $\mu \mathrm{g} / \mathrm{g}$ creatinine). Analytical results below the limit of detection (LOD) were substituted with a value of the LOD divided by the square root of 2 before statistical analysis. LODs (\%>LOD) for MEHP, MEOHP, MEHHP, MECPP and MCMHP were determined at $0.50(100 \%), 0.50(98.99 \%), 0.50(98.39 \%), 0.50(100 \%)$ and $0.10(100 \%) \mu g / L$, respectively.

\section{Serum thyroid hormone determination}

Measured quantification of serum levels of TT3, TT4, TSH, free T3 (FT3), FT4 using radioimmunoassay (Jiu Ding, China).

\section{The mRNA expression of NISIPAX-8ITTF-10TG and TPO determination}

Total RNA was extracted from the peripheral blood of participants using trizol reagent (Ambion Shanghai, China). Total RNA quantity and integrity were measured with an ultraviolet spectrophotometer (IMPLEN, Germany). First-strand cDNA synthesis was carried out on total RNA by reverse transcription PCR (ABI, USA). Finally, cDNA was used for real-time quantitative PCR (Stratagene, Japan) to determine the levels of mRNAs of NISIPAX-8ロTTF-1 $\square T G$ and TPO. The primers are shown in Table S3.The mRNA expression levels were quantified via the $2^{-\triangle C T}$ method.

\section{Statistical Analysis}

Descriptive statistics of participants' demographics were tabulated, along with the distributions of DEHP metabolite concentrations, and thyroid hormones. The dichotomous variables are represented by $\mathrm{N}$ (\%). The Approximate normal variables were represented by mean and standard deviation (sd), and the non-normal variables were represented by geometric mean, 95\% $\mathrm{Cl}$ and quartiles. Thyroid hormone and DEHP metabolite concentrations were stratified according gender.

Multivariate linear regression was used to explore the associations between thyroid hormones and urinary DEHP metabolite concentrations. Concentrations of $\mathrm{TT}_{4}$ and FT3 approximated normality and were used in statistical models untransformed, the distribution of $\mathrm{TT}_{3}, \mathrm{TSH}$ and $\mathrm{FT}_{4}$ concentration was non-normality and was therefore In-transformed for statistical analyses. Creatinineadjusted DEHP metabolite concentrations were also In-transformed. Gender, age, BMI, and per capita income were included as covariates. $\mathrm{BMI}$ was modeled as a continuous variable and others as dichotomous variables. The regression coefficients were calculated as changes 
in thyroid hormones for an interquartile range (IQR) increase in DEHP metabolite concentrations. In addition, the associations between thyroid hormone concentrations and urinary DEHP metabolites levels grouped in quartiles were assessed by regression models.

Data with normal and uniform variances were analyzed by one-way analysis of variance (ANOVA) and non-normal or non-uniform data were analyzed by Kruskal-Wallis test to compare thyroid hormone related genes mRNA expression levels. The DEHP metabolite concentrations were grouped in quartiles expressed as Q1, Q2, Q3 and Q4. Statistical significance was set at $p=0.05$. Data analysis was performed and analyzed using IBM SPSS software version 24.0 (IBM, USA).

\section{Results}

\section{Characteristics of Participants}

A total of 347 subjects were collected in this study, including 116 males (33.4\%) and 231 females (66.6\%).Age distribution ranged from 16 to 19 years old.69.7\% of the subjects lived in urban and $30.3 \%$ lived in rural areas. Those whose household per capita income was less than 3,000 Yuan/month and those whose household per capita income was more than 3,000 Yuan/month accounted for $51.3 \%$ and $48.7 \%$, respectively. The subjects' BMI was $(21.54 \pm 3.67) \mathrm{kg} / \mathrm{m}^{2}$.As shown in table 1 .

Table. 1 Demographic and socioeconomic characteristics of participants $(\mathrm{N}=347)$

\begin{tabular}{|c|c|c|}
\hline Variable & Categories & $\mathrm{n}(\%) / \pm s$ \\
\hline \multirow[t]{2}{*}{ Gender } & Males & $116(33.4)$ \\
\hline & Females & $231(66.6)$ \\
\hline \multirow[t]{2}{*}{ Age (years) } & $16 \sim 17$ & 85 (24.5) \\
\hline & $18 \sim 19$ & $262(75.5)$ \\
\hline \multirow[t]{2}{*}{ Household location } & Urban & $242(69.7)$ \\
\hline & Rural & $105(30.3)$ \\
\hline \multirow[t]{2}{*}{ Income(Yuan/month) } & $\otimes 3000$ & $178(51.3)$ \\
\hline & $\geq 3000$ & $169(48.7)$ \\
\hline $\mathrm{BMI}\left(\mathrm{kg} / \mathrm{m}^{2}\right)$ & - & $21.54 \pm 3.67$ \\
\hline
\end{tabular}

\section{The distributions and exposure levels of DEHP in Participants}

The DEHP exposure level and distributions of the study subjects are shown in Table 2.In this study, the limits of the detection of urinary metabolites MEHP, MEOHP, MEHHP, MEECPP and MCMHP were 0.50, 0.50, 0.50, 0.50 and 0.10 $\mu \mathrm{g} / \mathrm{L}$, respectively. Except for MEOHP (99.2\%) and MEHHP (98.7\%), the detection rates of all other DEHP metabolites were 100\%.Among DEHP metabolites, the GM of MECPP was $9.43 \mu \mathrm{g} / \mathrm{g}$ Crea, and the geometric mean of other metabolites was MCMHP $(5.79 \mu \mathrm{g} / \mathrm{g}$ CREA), MEOHP $(4.55 \mu \mathrm{g} / \mathrm{g}$ CREA $)$, MEHHP $(3.37 \mu \mathrm{g} / \mathrm{g}$ CREA $)$ and MEHP $\left(2.43 \mu \mathrm{g} / \mathrm{g}\right.$ CREA) from high to low, and the geometric mean of $\sum$ DEHP was $94.72 \mathrm{nmol} / \mathrm{g}$.

There were significant differences in the levels of DEHP metabolites among subjects of different ages and Household location $(P<0.05)$. The MEOHP level in urine of 18-19 year olds was significantly higher than that of 16-17 year olds. The levels of MEOHP, MEHHP, MCMHP and $\sum$ DEHP in urine of subjects living in urban areas were significantly lower than those from rural areas $(P<0.05)$. There was no significant difference in urinary DEHP metabolites among subjects of different genders and families with per capita monthly income ( $P>0.05$ ), but the levels of DEHP metabolites in females were slightly higher than those in males except for MCMHP. Correlation analysis results among DEHP metabolites were shown in Table S1, and DEHP metabolites showed significant positive correlation $(P<0.05)$.

\section{The distributions and levels of Thyroid hormone in Participants}

The blood thyroid hormone levels and distributions of the subjects were shown in Table 3. The serum levels of TT4 and FT3 were $(124.05 \pm 24.56) \mathrm{nmol} / \mathrm{L}$ and $(4.57 \pm 1.69) \mathrm{pmol} / \mathrm{L}$, respectively. The geometric mean of TT3 was $1.89 \mathrm{nmol} / \mathrm{L}$, that of FT4 was 10.01 $\mathrm{pmol} / \mathrm{L}$, and that of $\mathrm{TSH}$ was $2.56 \mu \mathrm{Ul} / \mathrm{mL}$. 
There were significant differences in the blood TT4 levels among the subjects of different ages $(P<0.05)$, and there was no significant difference in serum thyroid hormone levels among different genders, family location and family per capita monthly income $(P<0.05)$.

Table. 2 Distributions of the DEHP exposure levels among participants $\quad$ [GM $(95 \% C)]$

\begin{tabular}{|c|c|c|c|c|c|c|}
\hline Variable & $\begin{array}{l}\text { MEHP } \\
(\mu \mathrm{g} / \mathrm{g} \text { Crea })\end{array}$ & $\begin{array}{l}\text { MEOHP } \\
(\mu \mathrm{g} / \mathrm{g} \text { Crea) }\end{array}$ & $\begin{array}{l}\text { MEHHP } \\
(\mu \mathrm{g} / \mathrm{g} \text { Crea })\end{array}$ & $\begin{array}{l}\text { MECPP } \\
(\mu \mathrm{g} / \mathrm{g} \text { Crea })\end{array}$ & $\begin{array}{l}\text { MCMHP } \\
(\mu \mathrm{g} / \mathrm{g} \text { Crea })\end{array}$ & $\begin{array}{l}\sum \mathrm{DEHP} \\
(\mathrm{nmol} / \mathrm{L})\end{array}$ \\
\hline Total & $2.43(2.23,2.65)$ & $4.55(4.15,4.98)$ & $3.37(3.06,3.69)$ & $9.43(8.70,10.21)$ & $5.79(5.30,6.36)$ & $94.72(88.50,101.54)$ \\
\hline \multicolumn{7}{|l|}{ Gender } \\
\hline Male & $2.40(2.06,2.81)$ & $4.29(3.70,5.01)$ & $3.25(2.73,3.89)$ & $9.02(7.88,10.32)$ & $5.79(5.00,6.73)$ & $90.46(79.92,103.03)$ \\
\hline Female & $2.43(2.20,2.72)$ & $4.68(4.17,5.26)$ & $3.43(3.03,3.88)$ & $9.65(8.71,10.69)$ & $5.79(5.17,6.50)$ & $96.93(88.70,105.92)$ \\
\hline \multicolumn{7}{|c|}{ Age(years) } \\
\hline $16 \rrbracket 17$ & $2.14(1.75,2.67)$ & $3.81(3.06,4.69)$ & $2.96(2.34,3.76)$ & $7.71(6.48,9.51)$ & $5.37(4.47,6.55)$ & $84.49(72.28,100.00)$ \\
\hline $18 \rrbracket 19$ & $2.52(2.29,2.80)$ & $4.82(4 \cdot 37,5 \cdot 31) \star$ & $3.51(3.15,3.91)$ & $10.07(9.21,11.04) *$ & $5.94(5.38,6.56)$ & $98.30(90.65,106.63)$ \\
\hline \multicolumn{7}{|c|}{$\begin{array}{l}\text { Household } \\
\text { location }\end{array}$} \\
\hline Urban & $2.40(2.16,2.68)$ & $4.26(3.74,4.76)$ & $3.12(2.72,3.53)$ & $8.89(8.04,9.87)$ & $5.54(4.97,6.21)$ & $89.96(82.07,98.34)$ \\
\hline Rural & $2.46(2.10,2.92)$ & $5.30(4.54,6.12) *$ & $4.02(3.49,4.67) *$ & $9.43(8.69,10.25)^{*}$ & $6.43(5.49,7.56)$ & $106.67(93.95,121.35) *$ \\
\hline \multicolumn{7}{|l|}{$\begin{array}{l}\text { Per capita } \\
\text { income }\end{array}$} \\
\hline \multicolumn{7}{|l|}{$\begin{array}{l}\text { (Yuan / } \\
\text { month) }\end{array}$} \\
\hline$\nabla 3000$ & $2.41(2.14,2.72)$ & $4.83(4.27,5.50)$ & $3.37(2.91,3.88)$ & $9.86(8.85,10.98)$ & $6.24(5.59,7.02)$ & $98.28(88.89,108.34)$ \\
\hline$\geq 3000$ & $2.44(2.13,2.78)$ & $4.27(3.73,4.90)$ & $3.37(2.88,3.94)$ & $9.00(7.88,10.32)$ & $5.36(4.71,6.18)$ & $91.11(81.18,102.59)$ \\
\hline
\end{tabular}

$* P \otimes 0.05$

Table.3 Distributions of serum THs levels among participants [GM(95\%Cl)/]

\begin{tabular}{llllll} 
Variable & $\mathrm{TT}(\mathrm{nmol} / \mathrm{L})$ & $\mathrm{TT}(\mathrm{nmol} / \mathrm{L})$ & $\mathrm{TSH}(\mu \mathrm{Ul} / \mathrm{mL})$ & $\mathrm{FT3}(\mathrm{pmol} / \mathrm{L})$ & $\mathrm{FT4}(\mathrm{pmol} / \mathrm{L})$ \\
\hline Total & $1.89(1.82,1.96)$ & $124.05 \pm 24.56$ & $2.56(2.41,2.73)$ & $4.57 \pm 1.69$ & $10.01(9.69,10.35)$ \\
\hline Gender & & & & & \\
\hline Male & $1.94(1.83,2.07)$ & $123.73 \pm 24.40$ & $2.42(2.19,2.67)$ & $4.63 \pm 1.71$ & $10.08(2.43,2.85)$ \\
\hline Female & $1.87(1.78,1.96)$ & $124.21 \pm 24.69$ & $2.63(2.43,2.85)$ & $4.53 \pm 1.68$ & $9.97(9.59,10.40)$ \\
\hline Age(years) & & & & & \\
\hline $16 \otimes 17$ & $1.84(1.71,1.98)$ & $129.07 \pm 22.79$ & $2.48(2.20,2.88)$ & $4.40 \pm 1.60$ & $10.12(9.48,10.74)$ \\
\hline $18 \otimes 19$ & $1.91(1.84,2.00)$ & $122.43 \pm 24.93^{\star}$ & $2.58(2.41,2.78)$ & $4.62 \pm 1.72$ & $9.97(9.56,10.34)$ \\
\hline Household location & & & & & \\
\hline Urban & $1.91(1.83,2.00)$ & $125.07 \pm 24.76$ & $2.60(2.43,2.83)$ & $4.48 \pm 1.73$ & $9.99(9.60,10.35)$ \\
\hline Rural & $1.85(1.76,1.96)$ & $121.72 \pm 24.04$ & $2.47(2.24,2.72)$ & $4.76 \pm 1.59$ & $10.04(9.32,10.80)$ \\
\hline
\end{tabular}

Per capita income

(Yuan / month)

$\begin{array}{llllll}₫ 3000 & 1.89(1.80,1.98) & 123.41 \pm 22.93 & 2.42(2.23,2.66) & 4.56 \pm 1.62 & 9.98(9.50,10.51) \\ \geq 3000 & 1.90(1.79,2.01) & 124.73 \pm 26.21 & 2.71(2.51,2.96) & 4.57 \pm 1.77 & 10.03(9.59,10.48)\end{array}$




\section{Associations between Thyroid Hormones and Urinary DEHP Metabolites}

Since metabolites of DEHP exhibit estrogen-like activity after entering the body, subsequent analyses of this study were further stratified according to gender

The results of multiple linear regression analysis of urinary DEHP metabolite levels and THs levels of all subjects after adjusting covariates are shown in Table 4. The levels of TT4 had a significant negative linear correlation with urine MEOHP $[\beta=-3.599(95 \% \mathrm{Cl}=-7.002,-0.625)] \mathbb{}$ MEHHP $[\beta=-3.534(95 \% C l=-6.774,-0.633)] \otimes M E C P P[\beta=-4.375(95 \% C l=-7.697,-0.756)] \varangle \mathrm{MCMHP}[\beta=-4.397(95 \% C l=-7.522,-1.174)]$ and $\sum$ DEHP $\left.\left.[\beta=-5.223(95 \% C l=-9.880,-1.085)]=-9.880,-1.085\right)\right]$.

The levels of DEHP metabolites and THs of the subjects were divided into quartile groups, and the relationship between them was analyzed by ordered multi-classification logistic regression after the adjustment of covariables. The results showed that the levels of TT3 and TT4 in $\sum$ DEHP Q4 group were at least one grade lower than those in Q1 group (Pख0.05). The levels of TT4 in Q4 groups of MEOHP, MEHHP, MECPP and MCMHP were all decreased by at least one grade compared with those in Q1 group (P凶0.05).The FT3 levels in MECPP Q3 group was significantly lower than that in Q1(P凶0.05). The results were shown in the figure 1.

As shown in Table 5, there was a significant negative correlation between MEOHP and TT4 in male subjects $(P<0.05)$ \and the levels of FT4 were significant positive correlated with MEHP $[\beta=0.089(95 \% \mathrm{Cl}=-0.021,0.157)] \square \mathrm{MECPP}[\beta=0.106(95 \% \mathrm{Cl}=0.021,0.190)] \square \mathrm{MCMHP}[\beta$ $=0.106(95 \% \mathrm{Cl}=(0.029,0.183)]$ and $\sum \mathrm{DEHP}[\beta=0.121(95 \% \mathrm{Cl}=0.032,0.209)]$.

The results of ordered multi-classification logistic regression analysis in male subjects showed in figure 2. The TT4 level of MEOHP Q4 group in male subjects was significantly lower than that of Q1 group by at least one grade. The levels of FT3 in MEHP Q3 group was significantly higher than that in Q1 $(P<0.05)$.Compared with Q1 group, the level of FT4 in MEHP, MECPP and $\sum$ DEHP Q4 group was higher. The levels of FT4 in MCMHP Q3 and Q4 groups were increased by at least one grade compared with that in Q1 $(P<0.05)$.

Table 4. Associations of serum thyroid hormones with urinary DEHP metabolites in total participants [ $\beta(95 \% C l), \mathrm{N}=347]$.

\begin{tabular}{|llllll|}
\hline Total ${ }^{\text {a }}$ & Ln TT3 & TT4 & Ln TSH & FT3 & Ln FT4 \\
\hline Ln MEHP & $-0.013(-0.061,0.043)$ & $-1.279(-4.620,2.146)$ & $-0.045(-0.120,0.023)$ & $-0.042(-0.266,0.147)$ & $0.017(-0.023,0.058)$ \\
\hline Ln MEOHP & $-0.007(-0.066,0.059)$ & $-3.599(-7.002,-0.625) *$ & $-0.039(-0.113,0.036)$ & $0.051(-0.158,0.256)$ & $0.006(-0.032,0.046)$ \\
\hline Ln MEHHP & $0.002(-0.045,0.050)$ & $-3.534(-6.774,-0.633) *$ & $-0.035(-0.109,0.038)$ & $0.039(-0.157,0.227)$ & $0.010(-0.026,0.046)$ \\
\hline Ln MECPP & $-0.007(-0.058,0.051)$ & $-4.375(-7.697,-0.756) *$ & $-0.020(-0.100,0.062)$ & $-0.115(-0.349,0.116)$ & $0.013(-0.031,0.057)$ \\
\hline Ln MCMHP & $-0.001(-0.045,0.048)$ & $-4.397(-7.522,-1.174) * *$ & $-0.017(-0.084,0.051)$ & $-0.109(-0.314,0.106)$ & $0.028(-0.012,0.067)$ \\
\hline Ln $\sum$ DEHP & $-0.015(-0.076,0.048)$ & $-5.223(-9.880,-1.085) * *$ & $-0.054(-0.135,0.038)$ & $-0.074(-0.337,0.185)$ & $0.025(-0.025,0.074)$ \\
\hline
\end{tabular}

${ }^{a}$ Adjusted for age, gender, domicile, per capita income, and $\mathrm{BMI},{ }^{\star} P<0.05 .{ }^{* \star} P<0.01$.

Table 5. Associations of serum thyroid hormones with urinary DEHP metabolites in male participants $[\beta(95 \% C l), \mathrm{N}=116]$.

\begin{tabular}{|llllll|}
\hline Male & Ln TT3 & TT4 & Ln TSH & FT3 & Ln FT4 \\
\hline Ln MEHP & $-0.018(-0.553,0582)$ & $-1.228(-7.859,5.932)$ & $0.009(-0.113,0.130)$ & $-0.017(-0.374,0.340)$ & $0.089(0.021,0.157)$ * \\
\hline Ln MEOHP & $-0.050(-0.113,0.005)$ & $-5.994(-10.484,-1.855)$ & $-0.019(-0.183,0.164)$ & $0.114(-0.258,0.486)$ & $0.057(-0.015,0.129)$ \\
\hline Ln MEHHP & $-0.010(-0.311,0.756)$ & $-3.671(-7.929,1.051)$ & $0.054(-0.090,0.194)$ & $0.188(-0.148,0.525)$ & $0.048(-0.018,0.114)$ \\
\hline Ln MECPP & $-0.046(-0.118,0.033)$ & $-4.622(-11.052,1.738)$ & $0.100(-0.040,0.266)$ & $-0.027(-0.470,0.416)$ & $0.106(0.021,0.190) *$ \\
\hline Ln MCMHP & $-0.027(-0.092,0.045)$ & $-1.561(-7.519,3.920)$ & $0.034(-0.090,0.160)$ & $-0.075(-0.480,0.330)$ & $0.106(0.029,0.183) * *$ \\
\hline Ln *DEHP & $-0.039(-0.123,0.043)$ & $-4.815(-11.840,2.183)$ & $0.076(-0.054,0.243)$ & $0.043(-0.423,0.510)$ & $0.121(0.032,0.209) *$ \\
\hline
\end{tabular}

${ }^{a}$ Adjusted for age, domicile, per capita income, and $\mathrm{BMI},{ }^{\star} P<0.05,{ }^{\star \star} P<0.01$. 
The results of multiple linear regression analysis of urinary DEHP metabolite levels and THs levels of female subjects and the ordered multi-classification logistic regression after the adjustment of covariables were showed in Table 6 and figure3.In female subjects, the levels of TT4 was significantly negatively correlated with MECPP $[\beta=-4.158(95 \% C l=-8.722,0.211)] \otimes M C M H P[\beta=-5.284(95 \% C l=(-9.133,-1.613)]$ and $\sum$ DEHP $[\beta=-5.235(95 \% C l=-11.270,-0.034)]$.The levels of TSH was significantly negatively correlated with $\sum \mathrm{DEHP}(P \otimes 0.05)$.

The TT3 level of female subjects in $\sum$ DEHP Q4 group was at least one grade lower than that in Q1 group (P凶0.05), and the TT3 level of female subjects in MEHHP Q3 group was also significantly lower than that in Q1 group (P凶0.05). The levels of TT4 in MEOHP, MEHHP, McMHP and $\sum$ DEHP Q4 groups of female subjects were significantly lower than those in Q1 group (Pख0.05), and TT4 levels in MEHHP and $\sum$ DEHP Q3 groups were also significantly lower than those in Q1 group (P凶0.05). The TSH level of female subjects in MECPP and $\sum$ DEHP Q4 group was significantly lower than that in Q1 group (P冈0.05), and the level of TSH in MEHP Q3 group was significantly lower than that in Q1 group by at least one grade $(P \otimes 0.05)$

Table 6. Associations of serum thyroid hormones with urinary DEHP metabolites in female participants [ $\beta(95 \% C I), N=231]$.

\begin{tabular}{|llllll|}
\hline Female & Ln TT3 & TT4 & Ln TSH & FT3 & Ln FT4 \\
\hline Ln MEHP & $-0.014(-0.074,0.048)$ & $-1.232(-5.546,2.540)$ & $-0.084(-0.174,0.008)$ & $-0.085(-0.356,0.187)$ & $-0.022(-0.071,0.027)$ \\
\hline Ln MEOHP & $0.014(-0.070,0.094)$ & $-2.583(-7.444,1.337)$ & $-0.044(-0.131,0.038)$ & $0.022(-0.230,0.274)$ & $-0.017(-0.063,0.029)$ \\
\hline Ln MEHHP & $0.004(-0.062,0.079)$ & $-3.345(-7.661,0.492)$ & $-0.080(-0.159,-0.005)$ & $-0.059(-0.295,0.178)$ & $-0.004(-0.048,0.039)$ \\
\hline Ln MECPP & $-0.002(-0.071,0.064)$ & $-4.158(-8.722,0.211) *$ & $-0.086(-0.179,0.011)$ & $-0.199(-0.478,0.080)$ & $-0.019(-0.070,0.032)$ \\
\hline Ln MCMHP & $0.002(-0.052,0.063)$ & $-5.284(-9.133,-1.613) * *$ & $-0.045(-0.122,0.035)$ & $-0.149(-0.399,0.100)$ & $0.006(-0.040,0.051)$ \\
\hline Ln DDEHP & $-0.011(-0.095,0.074)$ & $-5.235(-11.270,-0.034) *$ & $-0.123(-0.231,-0.018) *$ & $-0.166(-0.485,0.154)$ & $-0.014(-0.072,0.044)$ \\
\hline
\end{tabular}

${ }^{a}$ Adjusted for age, domicile, per capita income, and BMI. ${ }^{*}<<0.05 .{ }^{* *} P<0.01$

Correlation between thyroid hormone levels and mRNA expression of key genes in thyroid hormone metabolism.

The correlation analysis results of the subjects' blood thyroid hormone levels and mRNA expression of key genes of thyroid hormone metabolism are shown in Table 7.There was a negative correlation between FT3 level and TG mRNA expression level in blood of all subjects $(P<0.05)$. The TT4 level of male was significantly correlated with the mRNA relative expression levels of TG, NIS and PAX$8(P<0.05)$.In female subjects, there was a significant negative correlation between FT3 level and TG mRNA level, and a significant negative correlation between FT4 level and NIS mRNA level (Table.7, $P<0.05$ ).

Table. 7 The correlation of THs related genes mRNA levels and THs levels 


\begin{tabular}{|llllll|}
\hline Variable & TPO & TG & NIS & TTF-1 & PAX-8 \\
\hline Total & & & & & \\
\hline TT3 & 0.086 & 0.057 & 0.068 & 0.019 & 0.077 \\
\hline TT4 & -0.002 & 0.024 & -0.035 & -0.039 & -0.055 \\
\hline TSH & -0.003 & 0.016 & 0.010 & 0.023 & 0.035 \\
\hline FT3 & -0.036 & $-0.119^{*}$ & 0.044 & -0.101 & -0.012 \\
\hline FT4 & -0.030 & -0.031 & -0.093 & -0.019 & -0.036 \\
\hline Male & & & & & \\
\hline TT3 & 0.005 & -0.050 & -0.015 & -0.042 & 0.025 \\
\hline TT4 & -0.175 & $-0.185^{*}$ & $-0.211^{*}$ & -0.129 & $-0.252^{*}$ \\
\hline TSH & 0.059 & 0.113 & 0.035 & 0.078 & 0.016 \\
\hline FT3 & 0.057 & -0.097 & 0.074 & -0.163 & 0.014 \\
\hline FT4 & -0.045 & -0.019 & -0.014 & 0.05 & 0.031 \\
\hline Female & & & & & \\
\hline TT3 & 0.120 & 0.107 & 0.111 & 0.045 & 0.107 \\
\hline TT4 & 0.075 & 0.106 & 0.048 & 0.009 & 0.040 \\
\hline TSH & -0.076 & -0.025 & -0.001 & -0.007 & 0.041 \\
\hline FT3 & -0.020 & $-0.132^{*}$ & 0.030 & -0.073 & -0.036 \\
\hline FT4 & -0.019 & -0.019 & $-0.146^{*}$ & -0.036 & -0.081 \\
\hline
\end{tabular}

$\star P \otimes 0.05$

Thyroid hormones related genes mRNA expression at different levels of DEHP metabolites.

In this study, the mRNA expression levels of thyroid hormone related genes TPO, TG, NIS, TTF-1 and PAX-8 in blood samples were analyzed by ordered multi-classification logistic regression. In total subjects, the relative mRNA expression level of TG in MECPP and MCMHP Q4 groups were higher than that in Q1 group, and the mRNA level of TTF-1 in MECPP, MCMHP, MCMHP and $\sum$ DEHP Q4 groups were higher than that in the Q1 group $(P<0.05)$.The mRNA level of $P A X-8$ in the MEHHP Q4 group was at least one grade higher than that in the Q1 group (Figure $4, P<0.05$ ).

In male subjects, the relative mRNA level of $T G$ in $\sum$ DEHP Q4 group was at least one grade higher than that in Q1 group $(P<0.05)$. The mRNA level of TTF-1 in $\sum$ DEHP Q2 and Q4 groups was at least one grade higher than that in Q1 group $(P<0.05)$. The mRNA level of $P A X-8$ in MEHHP and $\sum$ DEHP Q4 group was higher than that in Q1 group $(P<0.05)$. The results were showed in Figure 5.

As shown in figure 6, the mRNA level of NIS of female subjects in MECPP and MCMHP Q4 groups were significantly higher than that in Q1 group $(P<0.05)$.

\section{Discussion}

As we all know, our study is the first research about the effects of DEHP exposure on serum thyroid hormone levels in Chinese adolescents (16-19 years). We found a negative correlation between urinary DEHP metabolites and TT4 in adolescents. When participants were stratified by gender, this association was similar in women, while FT4 levels in male were positively correlated with MEHP, MECPP, MCMHP and $\sum$ DEHP. Our results suggested that DEHP exposure affects thyroid hormone levels in adolescents. 
Significant correlations between urinary DEHP metabolites and thyroid hormones have been reported in previous studies (Table 8). The significant correlations between the urinary DEHP metabolites (MEHHP, $\sum$ DEHP) and TT4 observed in the Korean adult population are similar to our results (Park et al. 2017). According to the analysis results from NHANES data, metabolites of DEHP, e.g., MEHP, MEHHP, MEOHP or MECPP, in adult urine were negatively correlated with TT4 (Kim et al. 2017, Meeker and Ferguson 2011). In addition, a 9-year follow-up birth cohort study in China reported that the TT4 levels were inversely associated with maternal urinary MEHHP, MEOHP and $\sum$ DEHP. Significant associations between urinary DEHP metabolite levels and thyroid hormones that were observed in our study are comparable to those reported previously (Huang et al. 2017b). The results were also generally consistent with experimental studies. DEHP exhibited thyroid hormone receptor antagonistic activity(Shen et al. 2009, Shi et al. 2011),it can impair thyroid function, significantly reduce circulatory T3 and T4 levels along with pathology changes of thyroid glands in rats (Hinton et al. 1986, Howarth et al. 2001, Liu et al. 2015, Poon et al. 1997, Price et al. 1988).In addition, DEHP can also act on thyroid follicular cells, leading to changes in thyroid hormone levels(Ghisari and Bonefeld-Jorgensen 2009, Wenzel et al. 2005a). However, the patterns of the associations often varied due to the differences in participants' characteristics, especially age and region (Boas et al. 2010, Meeker and Ferguson 2011). Our study did not find significant associations between DEHP metabolites and other thyroid hormones such as TSH and TT3. It should be noticed that the levels of DEHP metabolites in this study were lower than those in previous and reported studies (Meeker and Ferguson 2011). These differences in associations may be due to differences in DEHP exposure and thyroid hormone levels.

Table 8. Associations between DEHP metabolites and thyroid hormones in human studies. 


\begin{tabular}{|c|c|c|c|c|c|c|c|}
\hline Country & Population(N) & metabolite & T3 & $\mathrm{T} 4$ & FT3 & FT4 & TSH \\
\hline \multirow[t]{13}{*}{ China(This study) } & Students aged 16 to $20(347)$ & MEOHP & & $\downarrow$ & & & \\
\hline & & MEHHP & & $\downarrow$ & & & \\
\hline & & MECPP & & $\downarrow$ & & & \\
\hline & & MCMHP & & $\downarrow$ & & & \\
\hline & & $\sum \mathrm{DEHP}$ & & $\downarrow$ & & & \\
\hline & Male(116) & MEHP & & & & $\uparrow$ & \\
\hline & & MEOHP & & $\downarrow$ & & & \\
\hline & & MECPP & & & & $\uparrow$ & \\
\hline & & MCMHP & & & & $\uparrow$ & \\
\hline & & $\sum \mathrm{DEHP}$ & & & & $\uparrow$ & \\
\hline & Female(231) & MECPP & & $\downarrow$ & & & \\
\hline & & MCMHP & & $\downarrow$ & & & \\
\hline & & $\sum \mathrm{DEHP}$ & & $\downarrow$ & & & $\downarrow$ \\
\hline \multirow[t]{3}{*}{ Korea(Park et al. 2017) } & KoNEHS, adults aged 19 or over (6003) & MEOHP & & $\downarrow$ & & & \\
\hline & & MEHHP & & $\downarrow$ & & & \\
\hline & & $\sum \mathrm{DEHP}$ & $\uparrow$ & & & & \\
\hline U.S.(Kim et al. 2017) & NHANES(1829) & MEHHP & & $\downarrow$ & & $\downarrow$ & $\uparrow$ \\
\hline \multirow[t]{4}{*}{ China(Huang et al. 2017b) } & Pregnant aged 20 to 35 Boys(168) & MEOHPa & $\downarrow$ & $\downarrow$ & & & \\
\hline & Children aged 2 to 9 & MEHHPa & $\downarrow$ & $\downarrow$ & & & \\
\hline & & $\sum \mathrm{DEHP}^{\mathrm{a}}$ & & $\downarrow$ & & & \\
\hline & Girls(167) & MEHPb & & & & $\downarrow$ & \\
\hline \multirow[t]{8}{*}{ U.S.(Meeker and Ferguson 2011) } & NHANES, adults aged 20 or over(1346) & MEHP & & $\downarrow$ & & & \\
\hline & & MEOHP & $\downarrow$ & $\downarrow$ & & & \\
\hline & & MEHHP & $\downarrow$ & $\downarrow$ & & & \\
\hline & & MECPP & & $\downarrow$ & & & \\
\hline & Adolescents aged 12 to $19(329)$ & MEHP & $\uparrow$ & & & & \\
\hline & & MEHHP & $\uparrow$ & & & & $\uparrow$ \\
\hline & & MEOHP & $\uparrow$ & & & & $\uparrow$ \\
\hline & & MECPP & $\uparrow$ & & & & $\uparrow$ \\
\hline U.S.(Meeker et al. 2007) & Males recruited from a study(208) & MEHP & $\downarrow$ & & & $\downarrow$ & \\
\hline \multirow[t]{2}{*}{ Denmark(Boas et al. 2010) } & Children aged 4 to $9(845)$ & $\sum \mathrm{DEHP}$ & & & $\downarrow$ & & \\
\hline & Girls(342) & $\sum \mathrm{DEHP}$ & $\downarrow$ & & $\downarrow$ & & \\
\hline Belgium(Dirtu et al. 2013) & Non-obese females(30) & MECPP & & & & & $\uparrow$ \\
\hline
\end{tabular}

In this study, DEHP metabolites were detected in the urine samples of all subjects. Except for MEOHP (99.2\%) and MEHHP (98.7\%), all other metabolites could be detected $100 \%$, indicating that the population was generally exposed to DEHP. We found significant differences in DEHP exposure levels among people of different ages and different household locations. The results showed that the levels of MEOHP and MECPP in the 18-19 age group were higher than those in the 16-17 age group. Although there are few age groups in this study, it can still be inferred that age may be an influencing factor affecting DEHP exposure levels. The differences in the household locations of the 
population also lead to differences in DEHP exposure levels. Compared with the objects whose household located in the city, those household located in the countryside have higher levels of MEOHP, MEHHP, MECPP and $\sum$ DEHP. This may be due to the environmental differences between the household locations. The reason for the higher levels of DEHP exposure in rural areas may be related to DEHP pollution in soil and water. Rural areas are close to chemical and plastic products factories. The discharge of industrial water containing DEHP will also cause pollution of water and soil in rural areas, and enter the human body through various channels, resulting in high levels of human DEHP exposure.

Adolescence is a recognizable stage in human development growth(C.G.D. Brook 2012). Xie et al found that MEHP exposure was significantly associated with constitutional delays in growth and puberty (CDGP)(CM Xie et al. 2015).It was also found that young girls with premature breast development had higher serum concentrations of DEHP metabolites than the control (Colon et al. 2000). Previous studies have rarely explored the association between DEHP metabolites and thyroid hormones at this stage. A U.S. study of adolescents aged 12 to 19 found that urinary DEHP metabolites had a positive correlation with serum TT3 and TSH (Meeker and Ferguson 2011). But our research didn't find this correlation. There were different results achieved in earlier life periods. Significant correlation of DEHP metabolites with FT3 were observed in Danish children aged 4 to 9 years $\varangle$ but not with other hormones (Boas et al. 2010). Thyroid hormone levels change significantly before adulthood(Corcoran JM 1977). We speculated that differences in the levels of the DEHP exposure between different populations and age could be reasons for the different effects observed. Additionally, phthalate may potentially interact with other endocrine pathways, such as the hypothalamic-pituitary axis or androgen biosynthesis. Such complex in vivo effects might be expected to contribute to differences in effects according to age. Future investigation is necessary to confirm these associations and to elucidate the biological mechanisms behind these age differences.

When stratified by gender, different associations were observed in males and females, which suggested that the association of DEHP metabolites with thyroid hormones might be gender-dependent. The Danish study on children also illustrated this gender dependent changes, which significant associations of sum of DEHP metabolites with TT3 and FT3 were observed among girls but not boys (Boas et al. 2010). In addition, studies have shown that thyroid hormone levels in women were more likely to change abnormally, and the probability of suffering from thyroid disease was also higher. The gender-dependent associations of thyroid hormones have been reported in animal studies (Abdelouahab et al. 2008). The mechanism of gender-dependent association is not clearly explained yet, but differences in physiological and endogenous hormones between males and females may be important reasons (Abdelouahab et al. 2008, Arbuckle 2006, Hatch et al. 2010, Vahter et al. 2007). For example, estrogen can increase the concentration of TT4 in serum(K.B. Ain 1987). Meanwhile, DEHP is an estrogen-like hormone (Wang et al. 2017), the androgen axis can directly affect thyroid hormones, and the antiandrogen mechanism of DEHP can destroy the balance of thyroid hormones (Flood et al. 2013). It should be noted that our study did find a positive association between DEHP metabolites and serum FT4 in males, which is contrary to previous studies (Huang et al. 2017b, Kim et al. 2017, Meeker et al. 2007). Previous studies have been reported that androgen decreases the level of serum thyroid binding globulin (TBG) (Arafah 1994, Deyssig and Weissel 1993), while DEHP has anti-androgenic effects, which may increase the levels of T4 and FT4.

The results of epidemiological and experimental studies on the effects of DEHP on the thyroid are not uniform. For population studies, gender and age may be confounding factors or influencing factors, although we adjusted them during the analysis. Therefore, when assessing the association between DEHP metabolites and thyroid hormone levels in adolescents, we collected sufficient anthropometric and adolescent-related information for the study subjects. In addition, endocrine system including thyroid hormones had a feedback system. A negative association between urinary DEHP metabolites and TT4, but no significant association with other thyroid hormones in adolescents, suggest that DEHP may alter thyroid signaling without affecting circulatory levels of thyroid hormones. Indeed, an experimental study have reported that EDs affect thyroid hormone levels independent of thyroid hormone feedback mechanism (Kaneko et al. 2008), and circulating thyroid hormone levels may not reflect the effects of EDs on thyroid hormone actions in the target tissue (Gore et al. 2015).

To better assess the association at a molecular level, we measured the mRNA expression levels of thyroid hormone related genes $T P O, T G$, NIS, TTF-1 and PAX-8 in blood samples. Unlike in thyroid tissue, the expression of these genes in peripheral blood is very low. In thyroid tissue, TG has the highest expression level and is the main factor in the feedback regulation of thyroid hormone. It can regulate the growth of thyroid cells, regulate enzymes and coenzyme factors related to thyroid hormone synthesis, and participate in the synthesis and metabolism of THs. Detection of TG mRNA levels in peripheral blood leukocytes can also help distinguish benign and malignant thyroid nodules. Studies have shown that the peripheral blood TG mRNA level in the malignant thyroid nodule group was significantly higher than that in the benign nodule group. In this study, the TG mRNA level of the population was significantly positively correlated with the DEHP exposure level. We inferred the higher DEHP exposure level may be related to the occurrence of malignant thyroid nodules. The transcription factors TTF-1 and PAX-8 both play important roles in the normal development of the thyroid. PAX-8 is the main regulator of thyroid development and function. The transcription factor it encodes can participate in the growth of thyroid follicular cells and is closely

Page $12 / 22$ 
related to the occurrence of thyroid cancer.In thyroid tissue, PAX-8 can induce the expression of thyroid-specific genes such as TG, TPO and NIS (Ohno et al. 1999a). TTF-1 is a transcription factor containing a homology domain, which can regulate the expression of TPO and TG, and is considered to be an essential self-regulating component in the regulation of TSHR (Neumann et al. 2018). Other studies inferred that the abnormal regulation of TTF-1 can lead to the disorder of TPO synthesis (Civitareale et al. 1989). In this study, the level of TTF-1 mRNA was correlated with the level of thyroid hormone, and the subjects' DEHP exposure level was significantly linearly correlated with the level of TTF-1 mRNA. The exposure level of DEHP in men also affects the level of PAX-8 mRNA in the peripheral blood, while the mRNA level of TPO is not significantly correlated with the level of DEHP exposure. Therefore, we speculate that DEHP may affect the synthesis of TPO by changing the normal transcription of TTF-1 and PAX-8 in peripheral blood, thereby changing the level of THs.

Studies have shown that TG can interact with human immune cells in peripheral blood leukocytes, and may affect the levels of T4 and T3 in tissues and peripheral blood (Zhao et al. 2018). This study also found the correlation between TG mRNA levels in peripheral blood leukocytes and thyroid hormones, indicating that DEHP exposure may affect the body's thyroid hormone levels by changing the transcription of TG in peripheral blood leukocytes. NIS mediates the accumulation of iodide in the thyroid, but the role it plays in the blood is unclear. This study found that the relative levels of NIS mRNA in female subjects were different in the DEHP metabolites in the quartile groupings, and it is significantly related to the level of thyroid hormone. Although the current evidence cannot explain whether the expression of NIS in the blood has an effect on thyroid hormone, it can be inferred that NIS plays an important role in the effect of DEHP exposure on the metabolism of thyroid hormone in women. The mechanism remains to be studied.

The current research on the mechanism of DEHP exposure affecting thyroid hormone levels is mainly through animal and cell experiments. DEHP exposure can affect thyroid hormone levels by affecting the expression of key thyroid hormone enzymes and proteins, suggesting that DEHP exposure may change the normal transcription of some genes and then affect the normal secretion of thyroid hormone. However, there is no report on the relevant research on the effect of DEHP exposure on the mRNA level of key genes in thyroid hormone metabolism. Certainly, this study has the same limitations as previous studies. First, this is a cross-sectional study and the number of samples is limited, we are unable to draw definitive conclusions about the association between DEHP metabolites and thyroid hormones. In addition, the level of metabolites in the urine of the participants was measured only once, which usually only reflected the short-term exposure, and not be representative of the average body burden of the subject (Cox et al. 2016). Although a study has shown that a single urine sample can moderately predict an individual's exposure level (Hauser et al. 2004, Teitelbaum et al. 2008).

\section{Conclusion}

Overall, the negative association between DEHP exposure and TT4 in Chinese adolescents was found and the mRNA levels of TG, TTF-1 and $P A X-8$ in serum changed significantly in the different quartiles levels of DEHP metabolites. Our results enrich the research in this field. Considering the importance of thyroid hormones, the impact of environmental factors on thyroid hormones needs further study. Additional population or mechanism studies are necessary to confirm our results.

\section{Declarations}

\section{Ethical Approval}

This study was approved by the ethics committee of the School of Public Health, Jilin University, China.

\section{Consent to Participate}

Each subject was informed of the study protocol and provided written informed consent. If they agreed to be participants of the study, a consent form would be signed by the parent/guardian or the participant aged 18 and over.

\section{Funding Statement}

This study was supported by the National Natural Science Foundation of China (Grant No.81573184)

\section{Conflict of Interest}

The authors declare no conflict of interest

\section{Consent to Publish}

Not applicable 
Yaming Zhao, Lin Ye and Juwu Fu designed the studies. Yaming Zhao, Xinyue Song, Shuang Ding and Wen Qi performed the experiments. Yuezhu Zhang and Qi Xu analyzed the data and prepared the manuscript. Tianyang Zhao, Xueting Zhang, Xu Li performed all the figures, tables and polish the language. All authors reviewed and approved the final manuscript.

\section{Availability of data and materials}

The datasets used or analysed during the current study are available from the corresponding author on reasonable request.

\section{References}

1. [Anonymous]. 2012. Thyroid disease-more research needed. Lancet 379:1076.

2. Abdelouahab N, Mergler D, Takser L, Vanier C, St-Jean M, Baldwin M, et al. 2008. Gender differences in the effects of organochlorines, mercury, and lead on thyroid hormone levels in lakeside communities of quebec (canada). Environ Res 107:380-392.

3. Aldossari K, Al-Ghamdi S, Al-Zahrani J, Al Jammah A, Alanazi B, Al-Briek A, et al. 2019. Association between subclinical hypothyroidism and metabolic disorders: A retrospective chart review study in an emerging university hospital. J Clin Lab Anal 33.

4. Altmann A, Schulz RB, Glensch G, Eskerski H, Zitzmann S, Eisenhut M, et al. 2005. Effects of pax8 and ttf-1 thyroid transcription factor gene transfer in hepatoma cells: Imaging of functional protein-protein interaction and iodide uptake. J Nucl Med 46:831-839.

5. Arafah BM. 1994. Decreased levothyroxine requirement in women with hypothyroidism during androgen therapy for breast cancer. Ann Intern Med 121:247-251.

6. Arbuckle TE. 2006. Are there sex and gender differences in acute exposure to chemicals in the same setting? Environmental Research 101:195-204.

7. Are C, Shaha AR. 2006. Anaplastic thyroid carcinoma: Biology, pathogenesis, prognostic factors, and treatment approaches. Ann Surg Oncol 13:453-464.

8. Berger K, Eskenazi B, Kogut K, Parra K, Lustig RH, Greenspan LC, et al. 2018. Association of prenatal urinary concentrations of phthalates and bisphenol a and pubertal timing in boys and girls. Environ Health Perspect 126:97004.

9. Boas M, Frederiksen H, Feldt-Rasmussen U, Skakkebaek NE, Hegedus L, Hilsted L, et al. 2010. Childhood exposure to phthalates: Associations with thyroid function, insulin-like growth factor i, and growth. Environ Health Persp 118:1458-1464.

10. C.G.D. Brook MTD. 2012. Handbook of clinical pediatric endocrinology 2nd. (chapter 5): The management of growth disorders. WileyBlackwell 70-98.

11. Civitareale D, Lonigro R, Sinclair AJ, Di Lauro R. 1989. A thyroid-specific nuclear protein essential for tissue-specific expression of the thyroglobulin promoter. EMBO J 8:2537-2542.

12. Colon I, Caro D, Bourdony CJ, Rosario O. 2000. Identification of phthalate esters in the serum of young puerto rican girls with premature breast development. Environ Health Perspect 108:895-900.

13. Corcoran JM EC, Carter JN, Lazarus L. 1977. Circulating thyroid hormone levels in children. Arch Dis Child 52:716-720.

14. Cox KJ, Porucznik CA, Anderson DJ, Brozek EM, Szczotka KM, Bailey NM, et al. 2016. Exposure classification and temporal variability in urinary bisphenol a concentrations among couples in utah-the hope study. Environ Health Persp 124:498-506.

15. Deyssig R, Weissel M. 1993. Ingestion of androgenic-anabolic steroids induces mild thyroidal impairment in male body builders. J Clin Endocrinol Metab 76:1069-1071.

16. Di Jeso B, Arvan P. 2016. Thyroglobulin from molecular and cellular biology to clinical endocrinology. Endocr Rev 37:2-36.

17. Di Palma T, Nitsch R, Mascia A, Nitsch L, Di Lauro R, Zannini M. 2003. The paired domain-containing factor pax8 and the homeodomain-containing factor ttf-1 directly interact and synergistically activate transcription. Journal of Biological Chemistry 278:3395-3402.

18. Diamanti-Kandarakis E, Bourguignon JP, Giudice LC, Hauser R, Prins GS, Soto AM, et al. 2009. Endocrine-disrupting chemicals: An endocrine society scientific statement. Endocr Rev 30:293-342.

19. Ding S, Zhang Z, Chen Y, Qi W, Zhang Y, Xu Q, et al. 2019. Urinary levels of phthalate metabolites and their association with lifestyle behaviors in chinese adolescents and young adults. Ecotox Environ Safe 183:109541.

20. Dirtu AC, Geens T, Dirinck E, Malarvannan G, Neels H, Van Gaal L, et al. 2013. Phthalate metabolites in obese individuals undergoing weight loss: Urinary levels and estimation of the phthalates daily intake. Environ Int 59:344-353. 
21. Dobrzynska MM. 2016. Phthalates - widespread occurrence and the effect on male gametes. Part 2. The effects of phthalates on male gametes and on the offspring. Rocz Panstw Zakl Hig 67:209-221.

22. Earls AO, Axford IP, Braybrook JH. 2003. Gas chromatography-mass spectrometry determination of the migration of phthalate plasticisers from polyvinyl chloride toys and childcare articles. J Chromatogr A 983:237-246.

23. Esposito C, Miccadei S, Saiardi A, Civitareale D. 1998. Pax 8 activates the enhancer of the human thyroperoxidase gene. Biochem J 331 ( Pt 1):37-40.

24. Fabbro D, Pellizzari L, Mercuri F, Tell G, Damante G. 1998. Pax-8 protein levels regulate thyroglobulin gene expression. Journal of Molecular Endocrinology 21:347-354.

25. Flood DEK, Fernandino JI, Langlois VS. 2013. Thyroid hormones in male reproductive development: Evidence for direct crosstalk between the androgen and thyroid hormone axes. Gen Comp Endocr 192:2-14.

26. Gartner S, Balski M, Koch M, Nehls I. 2009. Analysis and migration of phthalates in infant food packed in recycled paperboard. J Agric Food Chem 57:10675-10681.

27. Ghisari M, Bonefeld-Jorgensen EC. 2009. Effects of plasticizers and their mixtures on estrogen receptor and thyroid hormone functions. Toxicology Letters 189:67-77.

28. Gore AC, Chappell VA, Fenton SE, Flaws JA, Nadal A, Prins GS, et al. 2015. Executive summary to edc-2: The endocrine society's second scientific statement on endocrine-disrupting chemicals. Endocr Rev 36:593-602.

29. Gorini F, lervasi G, Coi A, Pitto L, Bianchi F. 2018. The role of polybrominated diphenyl ethers in thyroid carcinogenesis: Is it a weak hypothesis or a hidden reality? From facts to new perspectives. Int J Environ Res Public Health 15.

30. Han X, Meng LL, Li YM, Li A, Turyk ME, Yang RQ, et al. 2019. Associations between exposure to persistent organic pollutants and thyroid function in a case-control study of east china. Environ Sci Technol 53:9866-9875.

31. Hatch EE, Nelson JW, Stahlhut RW, Webster TF. 2010. Association of endocrine disruptors and obesity: Perspectives from epidemiological studies. Int J Androl 33:324-332.

32. Hauser R, Meeker JD, Park S, Silva MJ, Calafat AM. 2004. Temporal variability of urinary phthalate metabolite levels in men of reproductive age. Environ Health Persp 112:1734-1740.

33. Hinton RH, Mitchell FE, Mann A, Chescoe D, Price SC, Nunn A, et al. 1986. Effects of phthalic acid esters on the liver and thyroid. Environ Health Perspect 70:195-210.

34. Howarth JA, Price SC, Dobrota M, Kentish PA, Hinton RH. 2001. Effects on male rats of di-(2-ethylhexyl) phthalate and di-nhexylphthalate administered alone or in combination. Toxicol Lett 121:35-43.

35. Huang HB, Chuang CJ, Su PH, Sun CW, Wang CJ, Wu MT, et al. 2017a. Prenatal and childhood exposure to phthalate diesters and thyroid function in a 9-year follow-up birth cohort study: Taiwan maternal and infant cohort study. Epidemiology 28 Suppl 1:S10-S18.

36. Huang HB, Chuang CJ, Su PH, Sun CW, Wang CJ, Wu MT, et al. 2017b. Prenatal and childhood exposure to phthalate diesters and thyroid function in a 9-year follow-up birth cohort study taiwan maternal and infant cohort study. Epidemiology 28:S10-S18.

37. Huang PC, Kuo PL, Guo YL, Liao PC, Lee CC. 2007. Associations between urinary phthalate monoesters and thyroid hormones in pregnant women. Hum Reprod 22:2715-2722.

38. K.B. Ain YM, S. Refetoff. 1987. Reduced clearance rate of thyroxine-binding globulin (tbg) with increased sialytion: A mechanism for estrogen-induced elevation of serum tbg concentration. Endocrinol Metab:689-696.

39. Kaneko M, Okada R, Yamamoto K, Nakamura M, Mosconi G, Polzonetti-Magni AM, et al. 2008. Bisphenol a acts differently from and independently of thyroid hormone in suppressing thyrotropin release from the bullfrog pituitary. Gen Comp Endocrinol 155:574-580.

40. Katsikantami I, Sifakis S, Tzatzarakis MN, Vakonaki E, Kalantzi OI, Tsatsakis AM, et al. 2016. A global assessment of phthalates burden and related links to health effects. Environ Int 97:212-236.

41. Khairy GA. 2004. Solitary thyroid nodule: The risk of cancer and the extent of surgical therapy. East Afr Med J 81:459-462.

42. Kim S, Kim S, Won S, Choi K. 2017. Considering common sources of exposure in association studies - urinary benzophenone-3 and dehp metabolites are associated with altered thyroid hormone balance in the nhanes 2007-2008. Environ Int 107:25-32.

43. Kloas W, Lutz I. 2006. Amphibians as model to study endocrine disrupters. Journal of Chromatography A 1130:16-27.

44. Kohn LD, Shimura H, Shimura Y, Hidaka A, Giuliani C, Napolitano G, et al. 1995. The thyrotropin receptor. Vitam Horm 50:287-384.

45. Koniecki D, Wang R, Moody RP, Zhu J. 2011. Phthalates in cosmetic and personal care products: Concentrations and possible dermal exposure. Environ Res 111:329-336.

46. Lin CY, Chen PC, Hsieh CJ, Chen CY, Hu A, Sung FC, et al. 2017. Positive association between urinary concentration of phthalate metabolites and oxidation of DNA and lipid in adolescents and young adults. Sci Rep-Uk 7.

Page 15/22 
47. Liu C, Zhao L, Wei L, Li L. 2015. Dehp reduces thyroid hormones via interacting with hormone synthesis-related proteins, deiodinases, transthyretin, receptors, and hepatic enzymes in rats. Environ Sci Pollut Res Int 22:12711-12719.

48. Meeker JD, Calafat AM, Hauser R. 2007. Di(2-ethylhexyl) phthalate metabolites may alter thyroid hormone levels in men. Environ Health Persp 115:1029-1034.

49. Meeker JD, Ferguson KK. 2011. Relationship between urinary phthalate and bisphenol a concentrations and serum thyroid measures in us adults and adolescents from the national health and nutrition examination survey (nhanes) 2007-2008. Environ Health Persp 119:1396-1402.

50. Miccadei S, De Leo R, Zammarchi E, Natali PG, Civitareale D. 2002. The synergistic activity of thyroid transcription factor 1 and pax 8 relies on the promoter/enhancer interplay. Molecular Endocrinology 16:837-846.

51. Motonaga K, Ota M, Odawara K, Saito S, Welsch F. 2016. A comparison of potency differences among thyroid peroxidase (tpo) inhibitors to induce developmental toxicity and other thyroid gland linked toxicities in humans and rats. Regul Toxicol Pharm 80:283290.

52. Neumann S, Eliseeva E, Boutin A, Barnaeva E, Ferrer M, Southall N, et al. 2018. Discovery of a positive allosteric modulator of the thyrotropin receptor: Potentiation of thyrotropin-mediated preosteoblast differentiation in vitro. J Pharmacol Exp Ther 364:38-45.

53. Nix P, Nicolaides A, Coatesworth AP. 2005. Thyroid cancer review 1: Presentation and investigation of thyroid cancer. Int J Clin Pract 59:1340-1344.

54. Ohno M, Zannini M, Levy O, Carrasco N, di Lauro R. 1999a. The paired-domain transcription factor pax8 binds to the upstream enhancer of the rat sodium/iodide symporter gene and participates in both thyroid-specific and cyclic-amp-dependent transcription. Mol Cell Biol 19:2051-2060.

55. Ohno M, Zannini M, Levy O, Carrasco N, Di Lauro R. 1999b. The paired-domain transcription factor pax8 binds to the upstream enhancer of the rat sodium/iodide symporter gene and participates in both thyroid-specific and cyclic-amp-dependermt transcription. Mol Cell Biol 19:2051-2060.

56. Park C, Choi W, Hwang M, Lee Y, Kim S, Yu S, et al. 2017. Associations between urinary phthalate metabolites and bisphenol a levels, and serum thyroid hormones among the korean adult population - korean national environmental health survey (konehs) $2012-2014$. Sci Total Environ 584:950-957.

57. Poon R, Lecavalier P, Mueller R, Valli VE, Procter BG, Chu I. 1997. Subchronic oral toxicity of di-n-octyl phthalate and di(2-ethylhexyl) phthalate in the rat. Food Chem Toxicol 35:225-239.

58. Price SC, Chescoe D, Grasso P, Wright M, Hinton RH. 1988. Alterations in the thyroids of rats treated for long periods with di-(2ethylhexyl) phthalate or with hypolipidaemic agents. Toxicol Lett 40:37-46.

59. Robinson L, Miller R. 2015. The impact of bisphenol a and phthalates on allergy, asthma, and immune function: A review of latest findings. Curr Environ Health Rep 2:379-387.

60. Rowdhwal SSS, Chen J. 2018. Toxic effects of di-2-ethylhexyl phthalate: An overview. Biomed Res Int 2018:1750368.

61. Schettler T. 2006. Human exposure to phthalates via consumer products. Int J Androl 29:134-139, discussion 181-135.

62. Shea KM, HIth CE. 2003. Pediatric exposure and potential toxicity of phthalate plasticizers. Pediatrics 111:1467-1474.

63. Shen OX, Du GZ, Sun H, Wu W, Jiang Y, Song L, et al. 2009. Comparison of in vitro hormone activities of selected phthalates using reporter gene assays. Toxicology Letters 191:9-14.

64. Shi W, Wang X, Hu G, Hao Y, Zhang X, Liu H, et al. 2011. Bioanalytical and instrumental analysis of thyroid hormone disrupting compounds in water sources along the yangtze river. Environ Pollut 159:441-448.

65. Shin DJ, Plateroti M, Samarut J, Osborne TF. 2006. Two uniquely arranged thyroid hormone response elements in the far upstream $5^{\prime}$ flanking region confer direct thyroid hormone regulation to the murine cholesterol 7alpha hydroxylase gene. Nucleic Acids Res 34:3853-3861.

66. Spanou I, Bougea A, Liakakis G, Rizonaki K, Anagnostou E, Duntas L, et al. 2019. Relationship of migraine and tension-type headache with hypothyroidism: A literature review. Headache 59:1174-1186.

67. Targovnik HM, Citterio CE, Rivolta CM. 2017. lodide handling disorders (nis, tpo, tg, iyd). Best Pract Res Clin Endocrinol Metab 31:195212.

68. Teitelbaum SL, Britton JA, Calafat AM, Ye X, Silva MJ, Reidy JA, et al. 2008. Temporal variability in urinary concentrations of phthalate metabolites, phytoestrogens and phenols among minority children in the united states. Environmental Research 106:257-269.

69. Trasande L, Sathyanarayana S, Trachtman H. 2014. Dietary phthalates and low-grade albuminuria in us children and adolescents. Clin J Am Soc Nephrol 9:100-109.

Page 16/22 
70. Vahter M, Akesson A, Liden C, Ceccatelli S, Berglund M. 2007. Gender differences in the disposition and toxicity of metals. Environ Res 104:85-95.

71. Vigneri R, Malandrino P, Giani F, Russo M, Vigneri P. 2017. Heavy metals in the volcanic environment and thyroid cancer. Mol Cell Endocrinol 457:73-80.

72. Wang X, Wang Y, Song Q, Wu J, Zhao Y, Yao S, et al. 2017. In utero and lactational exposure to di(2-ethylhexyl) phthalate increased the susceptibility of prostate carcinogenesis in male offspring. Reprod Toxicol 69:60-67.

73. Wenzel A, Franz C, Breous E, Loos U. 2005a. Modulation of iodide uptake by dialkyl phthalate plasticisers in frtl-5 rat thyroid follicular cells. Mol Cell Endocrinol 244:63-71.

74. Wenzel A, Franz C, Breous E, Loos U. 2005b. Modulation of iodide uptake by dialkyl phthalate plasticisers in frtl-5 rat thyroid follicular cells. Molecular and Cellular Endocrinology 244:63-71.

75. Xie C, Zhao Y, Gao L, Chen J, Cai D, Zhang Y. 2015. Elevated phthalates' exposure in children with constitutional delay of growth and puberty. Mol Cell Endocrinol 407:67-73.

76. Xie CM, Zhao Y, Gao LL, Chen J, Cai DP, Zhang YH. 2015. Elevated phthalates' exposure in children with constitutional delay of growth and puberty. Molecular and Cellular Endocrinology 407:67-73.

77. Ye HF, Ha M, Yang M, Yue P, Xie ZY, Liu CJ. 2017. Di2-ethylhexyl phthalate disrupts thyroid hormone homeostasis through activating the ras/akt/trhr pathway and inducing hepatic enzymes. Sci Rep-Uk 7.

78. Zhai W, Huang Z, Chen L, Feng C, Li B, Li T. 2014. Thyroid endocrine disruption in zebrafish larvae after exposure to mono-(2ethylhexyl) phthalate (mehp). Plos One 9:e92465.

79. Zhao M, Zhang X, Gao L, Song Y, Xu C, Yu C, et al. 2018. Palmitic acid downregulates thyroglobulin (tg), sodium iodide symporter (nis), and thyroperoxidase (tpo) in human primary thyrocytes: A potential mechanism by which lipotoxicity affects thyroid? Int $\mathrm{J}$ Endocrinol 2018:4215848.

80. Zhao X, Ren X, Ren B, Luo Z, Zhu R. 2016. Life-cycle exposure to bde-47 results in thyroid endocrine disruption to adults and offsprings of zebrafish (danio rerio). Environ Toxicol Pharmacol 48:157-167.

\section{Figures}
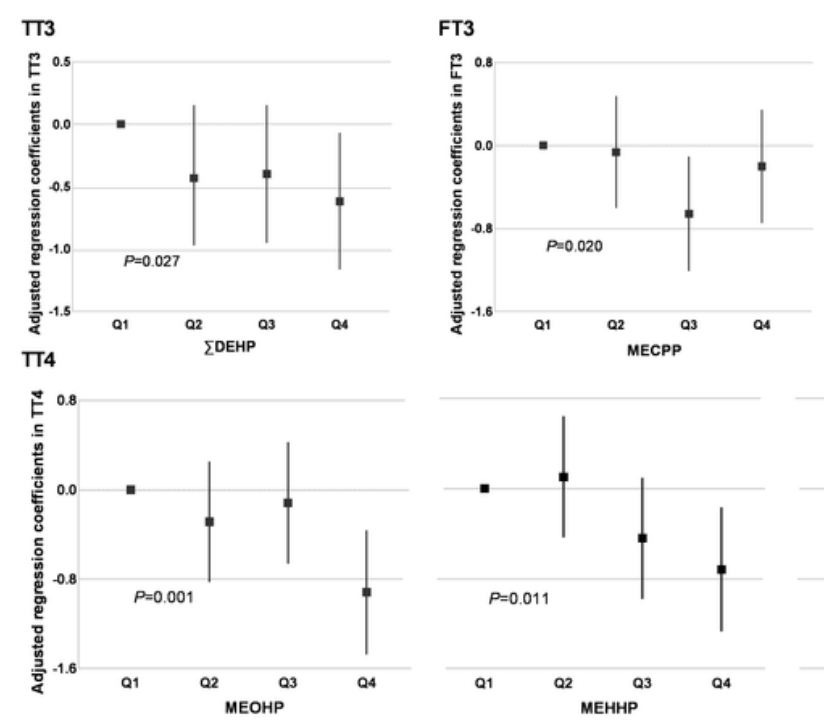

\section{Figure 1}

Regression coefficient for change in THs levels associated with quartiles change of DEHP exposure levels in total participants. Adjusted for gender, age, BMI, household location, and per capital income, N=347. 

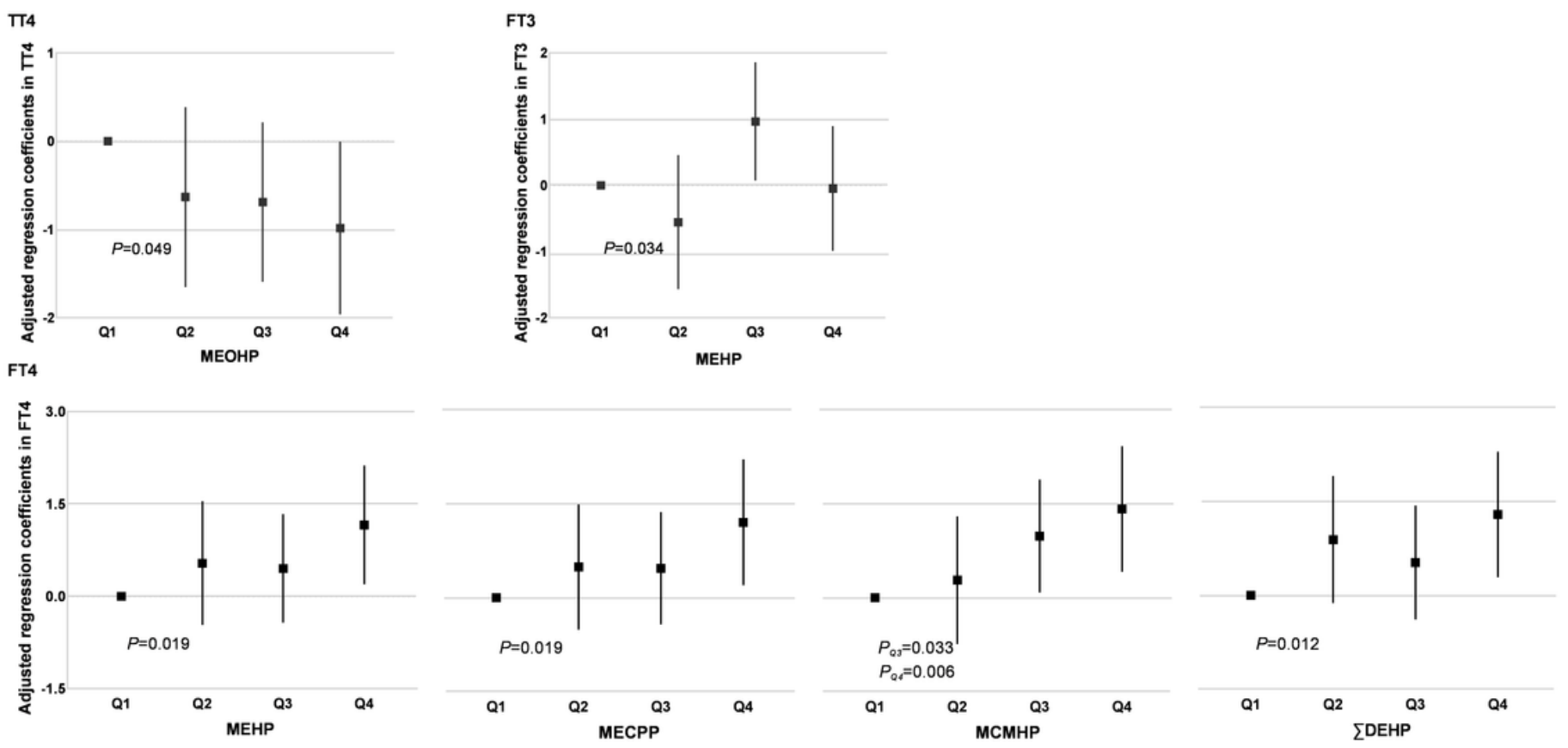

\section{Figure 2}

Regression coefficient for change in THs levels associated with quartiles change of DEHP exposure levels in male participants. Adjusted for age, BMI, household location, and per capital income, $\mathrm{N}=116$. 

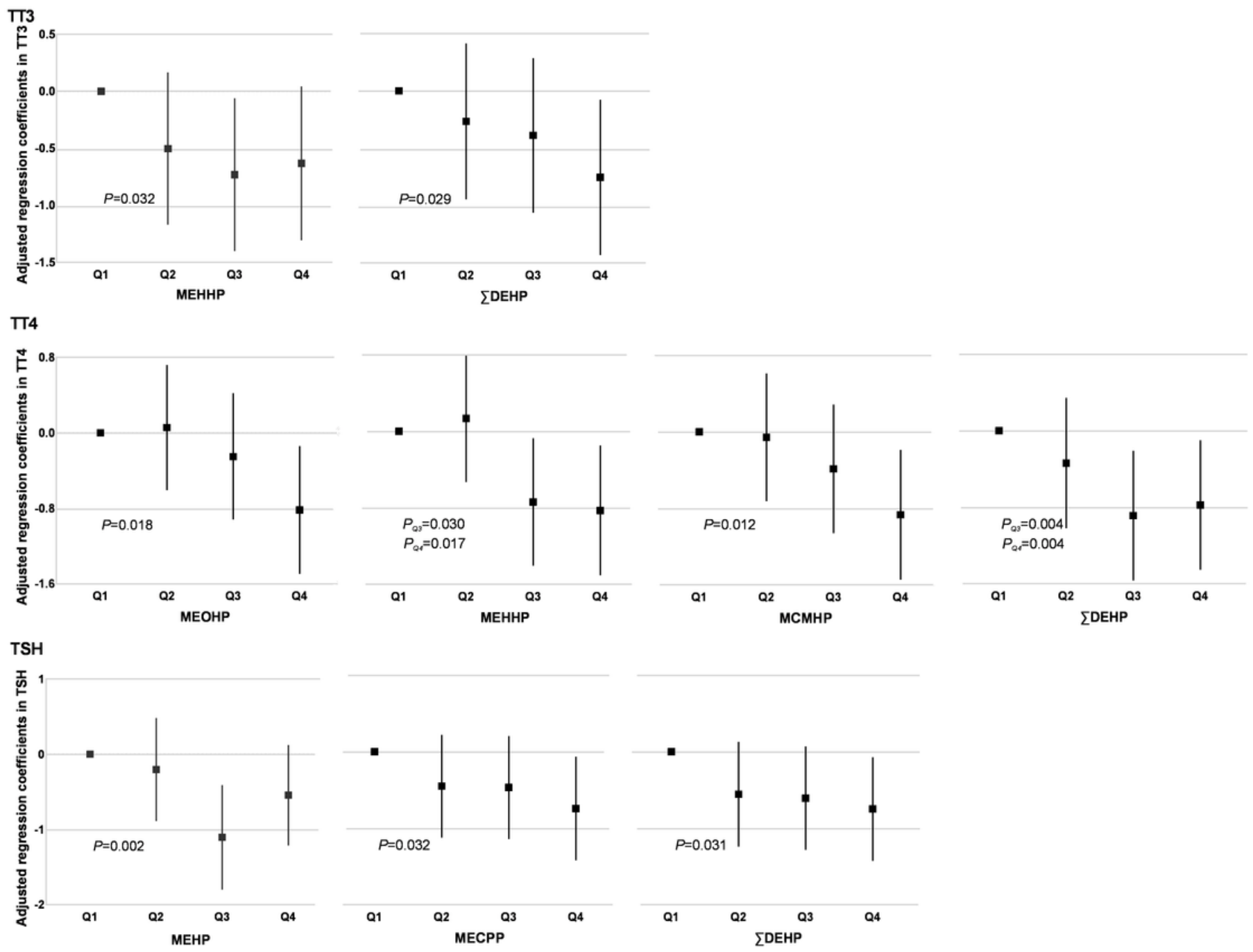

\section{Figure 3}

Regression coefficient for change in THs levels associated with quartiles change of DEHP exposure levels in female participants. Adjusted forage, BMI, household location, and per capital income, $\mathrm{N}=231$. 

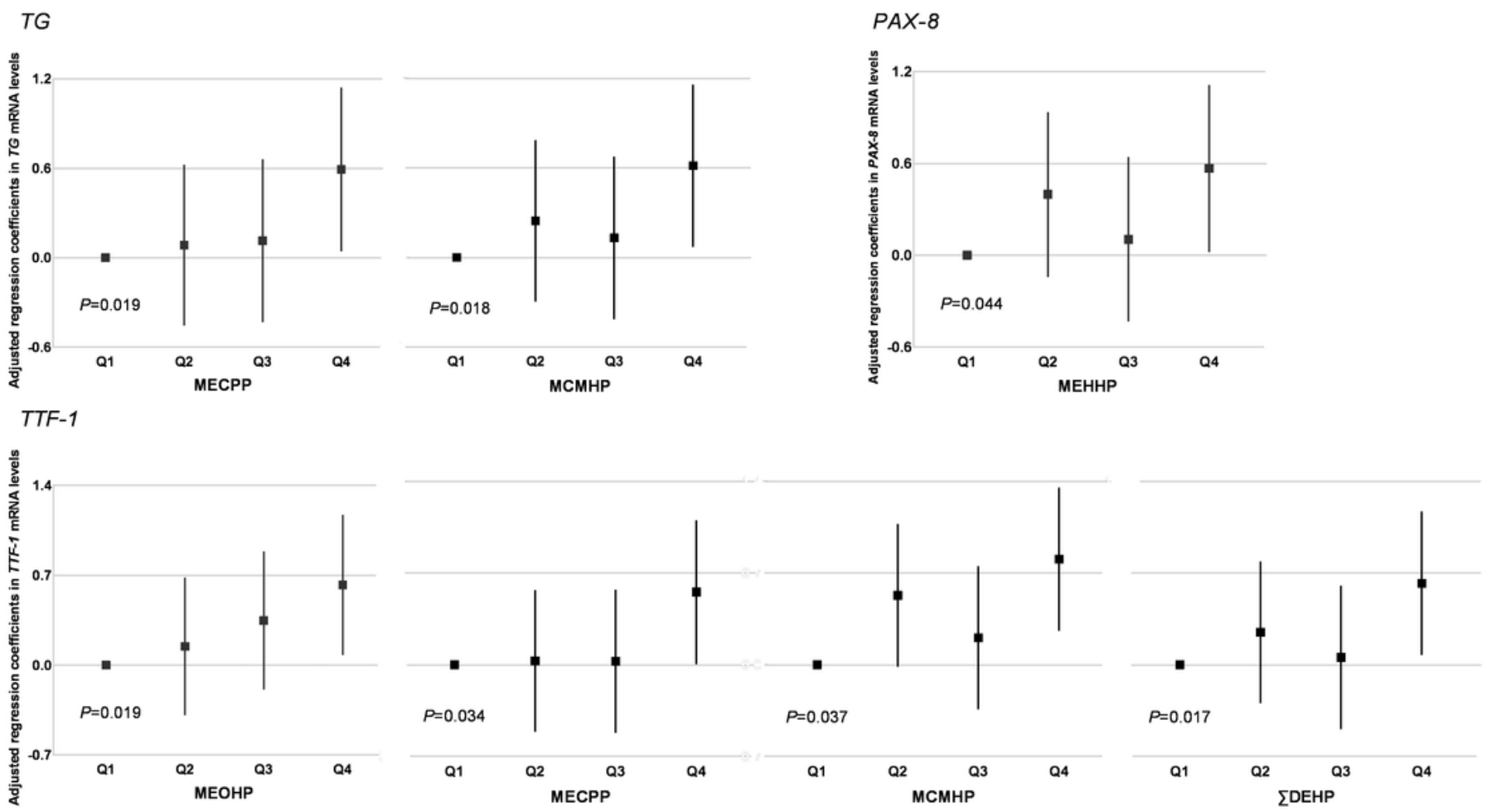

\section{Figure 4}

Regression coefficient for change in THs related genes mRNA levels associated with quartiles change of DEHP exposure levels in total participants Adjusted for gender, age, BMI, household location, and per capital income, N=347. 
TG

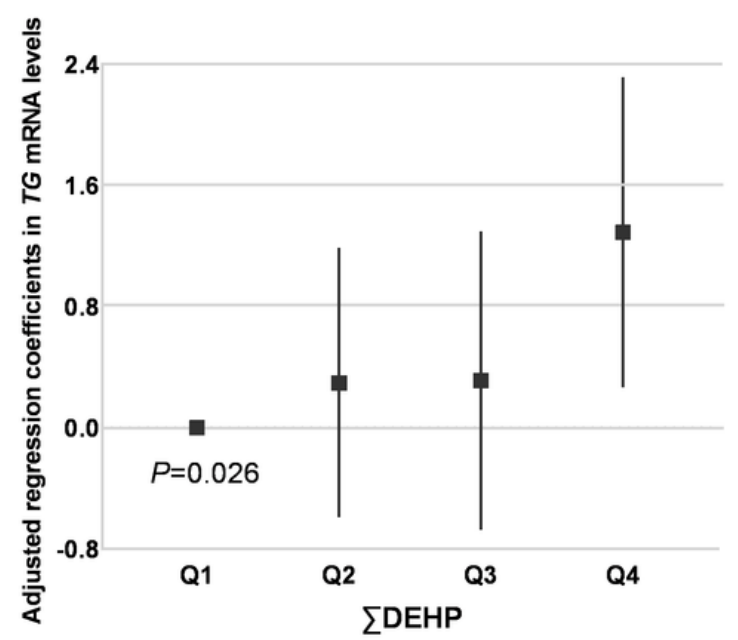

PAX-8

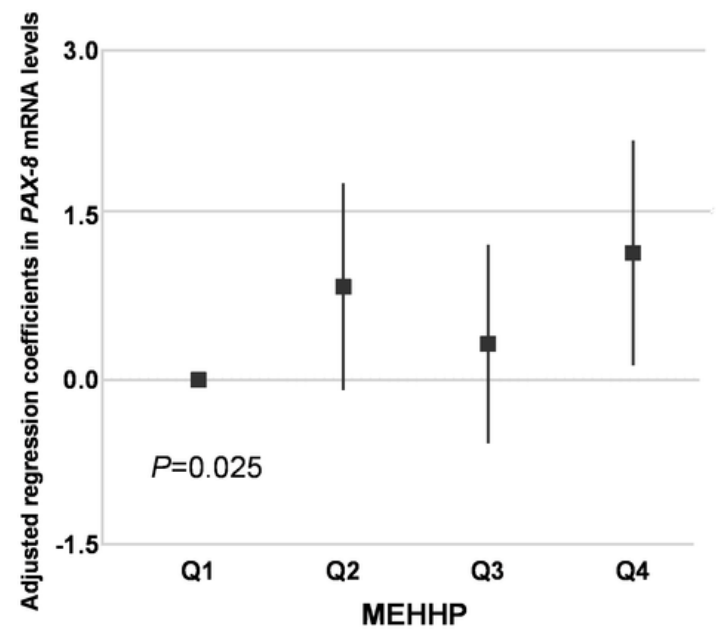

TTF-1

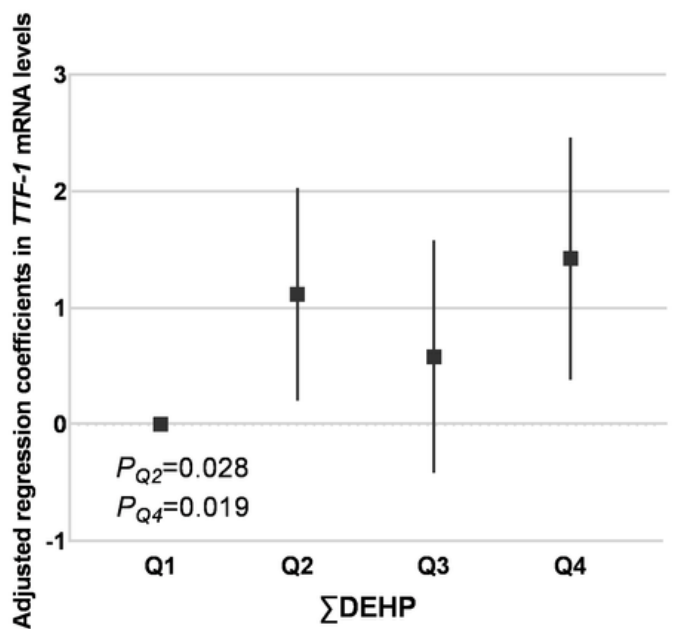

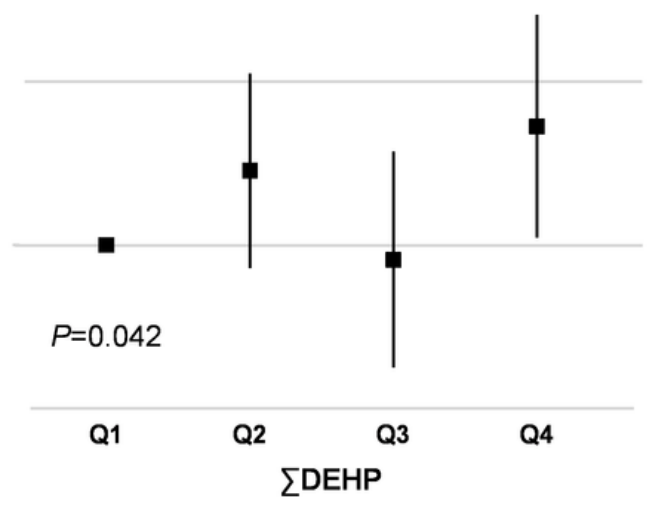

\section{Figure 5}

Regression coefficient for change in THs related genes mRNA levels associated with quartiles change of DEHP exposure levels in male participants Adjusted for age, BMI, household location, and per capital income, $\mathrm{N}=116$. 

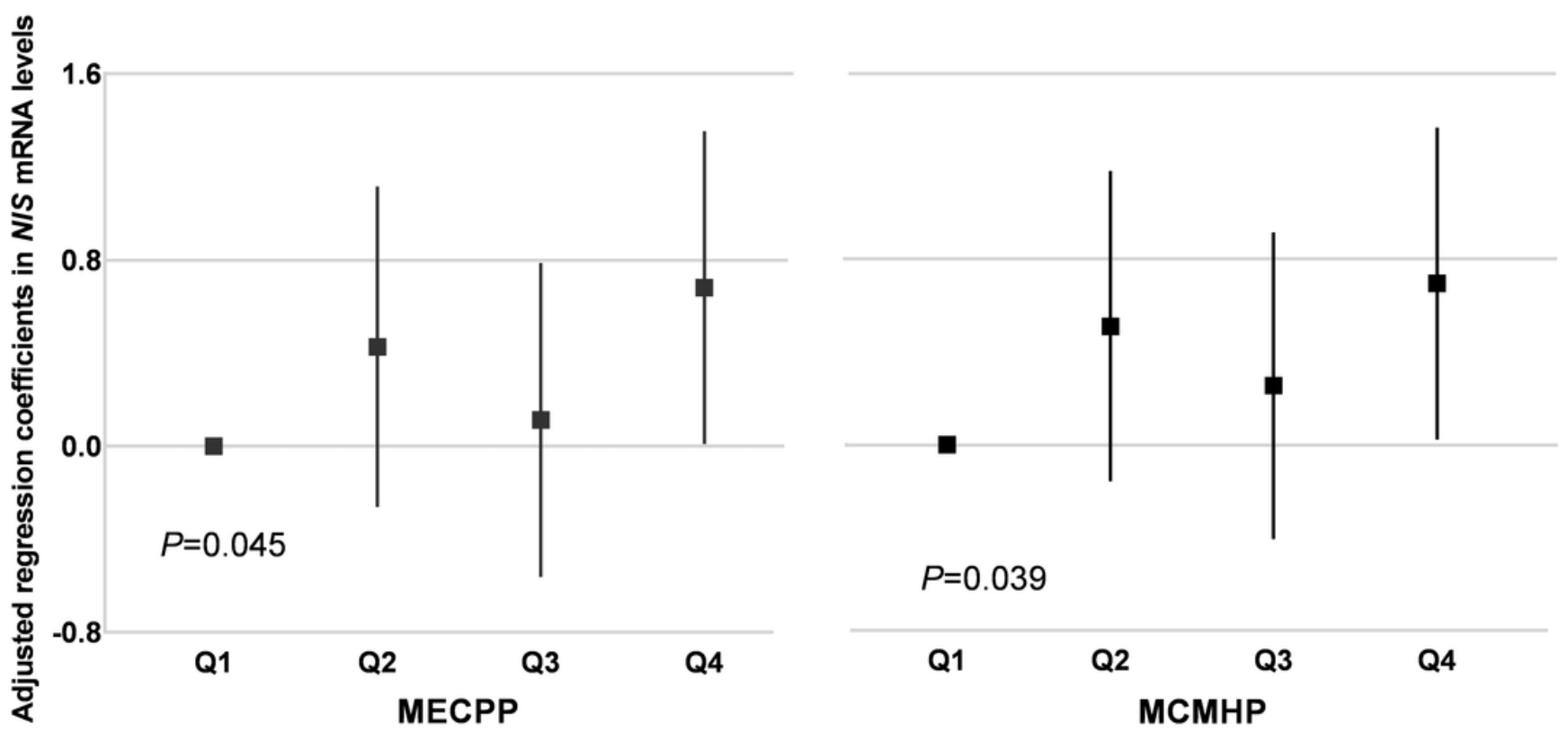

Figure 6

Regression coefficient for change in THs related genes mRNA levels associated with quartiles change of DEHP exposure levels in female participants Adjusted for gender, age, BMl, household location, and per capital income, $\mathrm{N}=231$.

\section{Supplementary Files}

This is a list of supplementary files associated with this preprint. Click to download.

- Supplementarydata.docx 